\title{
Galectin-1 $\beta$, a natural monomeric form of galectin-1 lacking its six amino-terminal residues promotes axonal regeneration but not cell death
}

\author{
T Miura ${ }^{1,2}$, M Takahashi $^{3}$, H Horie ${ }^{4}$, H Kurushima ${ }^{1,2}$, \\ D Tsuchimoto ${ }^{1,2}$, K Sakumi ${ }^{\star, 1,2}$ and $Y$ Nakabeppu ${ }^{1,2}$ \\ 1 Division of Neurofunctional Genomics, Department of Immunobiology and \\ Neuroscience, Medical Institute of Bioregulation, Kyushu University, Maidashi \\ Higashi-ku, Fukuoka, Japan \\ 2 Core Research for Evolutional Science and Technology (CREST), Japan \\ Science and Technology Agency (JST), Japan \\ ${ }^{3}$ Research Group FRE 2230, CNRS and Université de Nantes, Nantes, France \\ ${ }^{4}$ Advanced Research Center for Biological Science, Waseda University, 2-7-5 \\ Higashifushimi, Nishitokyo City, Tokyo, Japan \\ * Corresponding author: K Sakumi, 3-1-1 Maidashi, Higashi-ku, Fukuoka \\ 812-8582, Japan. Tel: + 8192642 6800; Fax: + 8192642 6791; \\ E-mail: sakumi@bioreg.kyushu-u.ac.jp
}

Received 02.3.04; revised 05.4.04; accepted 05.4.04; published online 04.6.04 Edited by $\mathrm{H}$ Ichijo

\section{Abstract \\ We previously identified a novel $\mathrm{N}$-terminally processed form of galectin-1, galectin-1 $\beta$ (Gal-1 $\beta$ ) whose expression was induced by $\Delta$ FosB. In the present study, the biochemical properties and biological functions of Gal-1 $\beta$ were compared with the full-length form of galectin-1 (Gal-1 $\alpha$ ). We first purified recombinant mouse Gal- $1 \alpha$ and $\beta$ (rmGal- $1 \alpha, \beta)$ to near homogeneity. The rmGal-1 $\alpha$ exists as a monomer under oxidized conditions and forms a dimer under reduced conditions, while the rmGal-1 $\beta$ exists as a monomer regardless of redox conditions. The affinity of rmGal- $1 \beta$ to $\beta$-lactose was approximately two-fold lower than that of rmGal-1 $\alpha$ under reduced conditions. The viability of Jurkat cells efficiently decreased when they were exposed to rmGal- $1 \alpha$, however, rmGal-1 $\beta$ barely induced such a reduction. In contrast, both rmGal- $1 \alpha$ and rmGal-1 $\beta$ exhibited an equivalent capacity to promote axonal regeneration from the dorsal root ganglion explants. Our results suggest that the biochemical properties of rmGal-1 $\beta$ determine its biological functions. \\ Cell Death and Differentiation (2004) 11, 1076-1083. \\ doi:10.1038/sj.cdd. 4401462 \\ Published online 4 June 2004}

Keywords: galectin-1; $\triangle \mathrm{FosB}$; redox; cell viability; axonal regeneration

Abbreviations: Gal-1, Galectin-1; AP-1, activator protein-1; $\beta$-ME, $\beta$-mercaptoethanol; CD, circular dichroism; DRG, dorsal root ganglion

\section{Introduction}

In mammals, the regulation of the cell fate to either proliferate, differentiate, arrest cell growth, or initiate programmed cell death is the most fundamental mechanism to maintain normal cell function and tissue homeostasis. Under multiple signaling pathways, Jun and Fos family proteins play important roles as components of an AP-1 (activator protein-1) complex, ${ }^{1,2}$ to regulate the transcription of various genes involved in cell proliferation, differentiation, and programmed cell death. ${ }^{3,4}$ We previously reported that $\triangle F O S B$, one of $A P-1$ subunits encoded by alternatively spliced fos $B$ mRNA, ${ }^{5}$ triggers one round of proliferation in the quiescent rat embryo cell lines, rat3Y1 and rat1a, followed by a different cell fate such as morphological alteration or delayed cell death, respectively. ${ }^{6,7}$ As one of the downstream targets of $\Delta \mathrm{FosB}$ in rat3Y1 cell line, we identified a novel form of rat galectin-1 whose $\mathrm{N}$-terminal residue corresponds to the seventh residue of the alreadyknown form of galectin-1 (Gal-1 $\alpha$ ). We named this novel processed form of galectin-1 as galectin-1 $\beta$ (Gal-1 $\beta) .{ }^{6}$ We have previously shown that the expression of galectin-1 is required for the proliferative activation of quiescent rat 1 a cells by $\Delta$ FosB, indicating that galectin-1 is one of the functional targets of $\Delta \mathrm{FosB}$ to modulate cell fate. ${ }^{7}$

Galectin family protein is defined by its affinity for $\beta$-galactoside sugars and shared amino-acid sequence which encodes the carbohydrate-binding-domain (CRD), ${ }^{8}$ and 10 mouse proteins are now registered in the database. Galectin1 , one of the well-studied proteins among the known galectin families is a $14.5-\mathrm{kDa}$ protein with a single CRD in the molecule. Galectin-1 is expressed in many tissues including skeletal muscle, liver, spleen, and lung. ${ }^{9-14}$ It has been documented that galectin-1 is a multifunctional molecule involved in the regulation of either cell-cell ${ }^{15}$ or cellextracellular matrix adhesion, ${ }^{16}$ cell proliferation, ${ }^{7,17}$ programmed cell death, ${ }^{18,19}$ the Ras signaling pathway, ${ }^{20,21}$ and is also related to the mRNA splicing mechanism. ${ }^{22,23}$

The amino-terminal alanine residue of $\mathrm{Gal}-1 \alpha$ is acetylated after the removal of the first methionine residue (Figure 1a) ${ }^{24}$ and $\mathrm{Gal}-1 \alpha$ forms a homodimer in physiological conditions (Figure 1b). ${ }^{25,26}$ Recently, it has been shown that a monomeric form of oxidized Gal- $1 \alpha$ strongly promotes axonal regeneration after axotomy in the peripheral nerves. ${ }^{27-29}$ Because Gal- $1 \beta$ lacks the N-terminal six residues, which were reported to be important for the dimer formation of Gal- $1 \alpha^{26,30}$ (Figure 1a), it is most likely that Gal-1 $\alpha$ and Gal-1 $\beta$ exhibit distinct biological functions with different biochemical properties.

To explore the distinct biochemical properties of Gal-1 $\beta$, the recombinant proteins of mouse Gal-1 $\alpha$ and Gal-1 $\beta$ were expressed in Escherichia coli cells and then were purified to near homogeneity. In the present study, we report that the affinity of $\mathrm{Gal}-1 \beta$ to lactose is 2.27 -fold lower than that of $\mathrm{Gal}-1 \alpha$ and $\mathrm{Gal}-1 \beta$ is present in a monomeric form regardless of the redox conditions, and that $\mathrm{Gal}-1 \beta$ promotes axonal regeneration as does $\mathrm{Gal}-1 \alpha$, however, it has much less cytotoxicity. 
a

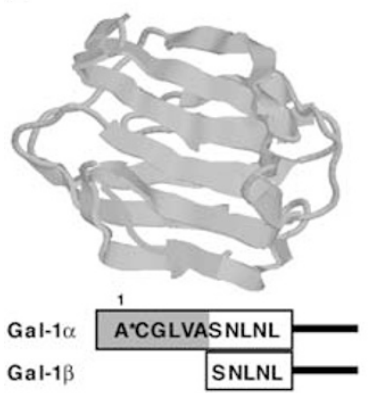

b

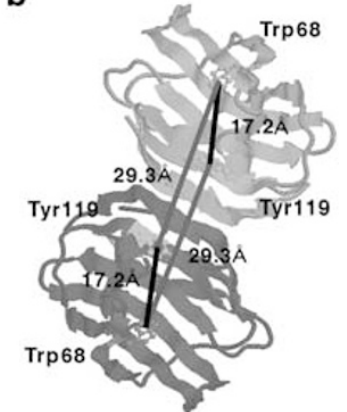

Figure 1 Crystal structure of galectin-1. (a) The structure of a bovine heart galectin-1 (Gal-1 $\alpha$ ). Six amino-acid residues which are missing in Gal-1 $\beta$ are shown in dark gray and the acetylated alanine at the N-terminus of Gal- $1 \alpha$ is refered as the first residue in the present study. The amino-acid sequences of $\mathrm{N}$ terminal parts of Gal- $1 \alpha$ and Gal- $1 \beta$ are also shown. (b) The structure of Gal-1 $\alpha$ homodimer. The crystal structure of bovine Gal- $1 \alpha$ dimer (PDB 1SLA) are shown by Protein Explorer. ${ }^{50}$ The Trp68 and Tyr119 residues are shown with the side chains. The distance between Trp68 and Tyr119 of the same molecule and that of another molecule formed homodimer are shown

\section{Results}

\section{Expression and purification of rmGal-1 $\alpha$ and rmGal-1 $\beta$}

Amino-acid sequences of galectin-1 are well conserved among mammals, and more than $90 \%$ of them are identical among rat, mouse, and human. In the present study, we prepared and characterized recombinant mouse Gal- $1 \alpha$ and Gal-1 $\beta$ (rmGal-1 $\alpha, \beta)$.

Both $\mathrm{rmGal}-1 \alpha$ and $\mathrm{rmGal}-1 \beta$ expressed in $E$. colicells were soluble in the presence of $14 \mathrm{mM} \beta$-ME, and thus were purified by affinity chromatography with lactose-agarose. During affinity chromatography, we found that a substantial amount of rmGal- $1 \beta$, but not rmGal- $1 \alpha$, was recovered in the flowthrough fractions (data not shown). The rmGal-1 $\beta$ that was recovered in the flow-through fractions is not an inactivated form because when it was reapplied onto the same column, essentially the same elution pattern was obtained.

An SDS-PAGE analysis revealed that each preparation of rmGal- $1 \alpha$ and rmGal- $1 \beta$ was almost nearly homogenous (Figure 2a), and their molecular mass determined by the MALDI-TOF analysis was 14734.2 and $14220.2 \mathrm{Da}$, respectively (Figure $2 \mathrm{~b}, \mathrm{c}$ ). The values correspond to the molecular mass of each protein lacking the $\mathrm{N}$-terminal methionine residue.

\section{The secondary structures of rmGal-1 $\beta$}

rmGal- $1 \beta$ lacks six residues present in the $\mathrm{N}$-terminus of rmGal- $1 \alpha$. To examine whether this difference affected in the secondary structures between rmGal- $1 \alpha$ and $\mathrm{rmGal}-1 \beta$, the $C D$ spectrum of each protein was measured (Figure $3 a$ ). The $C D$ spectra of both proteins exhibited a major negative peak around $215 \mathrm{~nm}$, and this peak of rmGal-1 $\beta$ was about $15 \%$ weaker in intensity than that of $r \mathrm{mGal}-1 \alpha$, suggesting that each protein has similar secondary structures of which major components are $\beta$-sheet structure, ${ }^{31,32}$ and that rmGal- $1 \beta$ lacks the $\mathrm{N}$-terminal $\beta$-sheet.
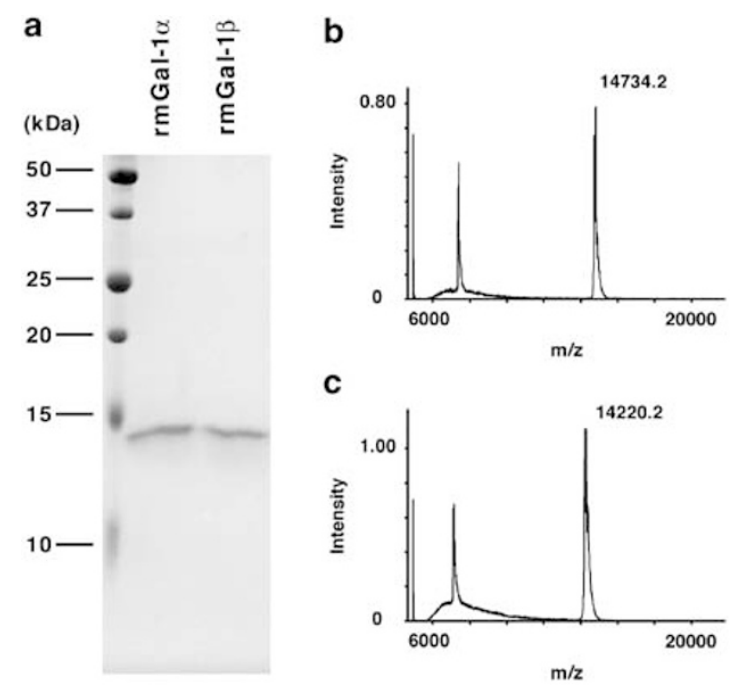

Figure 2 Purified preparations of rmGal- $1 \alpha$ and rmGal- $1 \beta$. (a) $1 \mu \mathrm{g}$ of purified rmGal- $1 \alpha$ and rmGal- $1 \beta$ were separated on a $15 \%$ SDS-PAGE gel. (b, c) MALDITOF mass spectrometric analyses of rmGal- $1 \alpha(\mathbf{b})$ and $r m G a l-1 \beta$ (c)
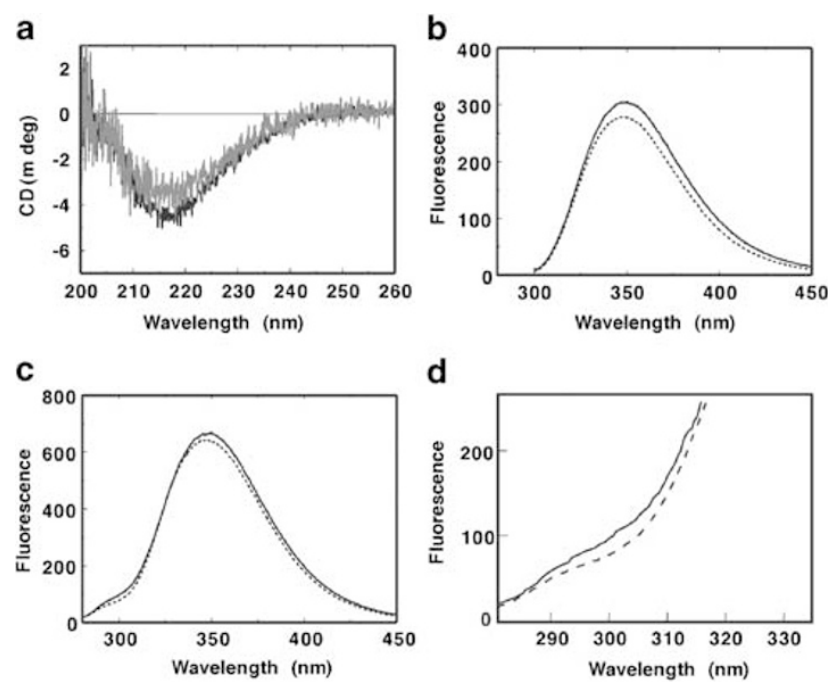

Figure $3 \mathrm{CD}$ spectra and intrinsic fluorescence emission spectra of $r \mathrm{mGal}-1 \alpha$ and rmGal-1 $1 \beta$. (a) CD spectra of rmGal- $1 \alpha$ and rmGal-1 $1 \beta$. CD spectra of $0.01 \mathrm{mg} / \mathrm{ml} \mathrm{rmGal}-1 \alpha$ (black line) and $\mathrm{rmGal}-1 \beta$ (gray line) were measured. (b, c) The fluorescence emission spectra of rmGal- $1 \alpha$ and rmGal-1 $\beta$. The emission spectra of rmGal- $1 \alpha$ (dashed line) and $\mathrm{rmGal}-1 \beta$ (solid line) were measured under the same conditions as in CD measurement with excitation at $295 \mathrm{~nm}$ (b) or at $270 \mathrm{~nm}$ (c). (d) The difference between the fluorescence emission spectra of rmGal- $1 \alpha$ and that of rmGal- $1 \beta$ with excitation at $270 \mathrm{~nm}$. The short-range emission spectra $(280-330 \mathrm{~nm}$ ) of rmGal- $1 \alpha$ (dashed line) and rmGal-1 $\beta$ (solid line) are shown

We next examined the protein fluorescence of rmGal-1 $\alpha$ and $\mathrm{rmGal}-1 \beta$. Gal- $1 \alpha$ has a single residue of tryptophan (Trp68) and tyrosine (Tyr119), which are conserved at the corresponding positions of Gal- $1 \beta{ }^{25,33}$ Upon selective excitation of tryptophan residue at $295 \mathrm{~nm}$, emission spectrum of rmGal- $1 \alpha$ peaked at $348 \mathrm{~nm}$ (Figure $3 \mathrm{~b}$ ), and that of rmGal- $1 \beta$ peaked at $351 \mathrm{~nm}$ (Figure 3b)

We also measured protein fluorescence with excitation at $270 \mathrm{~nm}$, which came from both tryptophan and tyrosine 
residues. The emission spectra of $\mathrm{rmGal}-1 \alpha$ and $\mathrm{rmGal}-1 \beta$ with excitation at $270 \mathrm{~nm}$ exhibited a small additional peak around $300 \mathrm{~nm}$ (Figure $3 \mathrm{c}, \mathrm{d}$ ) that from tyrosine residue, ${ }^{34}$ and this peak was larger from rmGal-1 $\beta$ than $r m G a l-1 \alpha$. In addition, the intensity of tryptophanyl fluorescence around $350 \mathrm{~nm}$ for rmGal-1 $\beta$ was almost the same as that for rmGal$1 \alpha$, while it was larger when excited at $295 \mathrm{~nm}$. The ratio of intensity of tryptophanyl fluorescence at $360 \mathrm{~nm}$ with excitation at 270 and $295 \mathrm{~nm}\left(l_{\text {ex270 }} / l_{\text {ex295 }}\right)$ was higher for rmGal-1 $\alpha$ than for $\mathrm{rmGal}-1 \beta$. This fact revealed that the fluorescence energy transfer from Tyr119 to Trp68 residues occurs more efficiently in rmGal- $1 \alpha$ than in rmGal- $1 \beta$. Indeed, the estimated distance between Trp68 residue in one subunit and Tyr119 in another subunit of a Gal- $1 \alpha$ dimer is $29.3 \AA$, and is close enough for efficient energy transfer (Figure 1b). ${ }^{34}$

\section{rmGal-1 $\beta$ exists as a monomer while rmGal-1 $\alpha$ forms a homodimer under reduced conditions}

Gal- $1 \alpha$ has been reported to form a homodimer in a concentration-dependent manner, ${ }^{35}$ and that hydrophobic aminoacid residues at both $\mathrm{N}$ - and $\mathrm{C}$-terminal parts are important in its dimerization. ${ }^{26,30}$

We performed a size-exclusion HPLC analysis to separate the dimer and monomer forms of rmGal- $1 \alpha$ and rmGal-1 $\beta$ (Figure 4). To avoid their spontaneous oxidation during the experiments, each protein was prepared in PBS containing $4 \mathrm{mM} \beta$-ME and the same buffer was used as the solvent for HPLC. Under our conditions, the retention time of each preparation was $9.5 \mathrm{~min}$ for $\mathrm{rmGal}-1 \alpha$ and $10.5 \mathrm{~min}$ for rmGal$1 \beta$ (Figure $4 \mathrm{a}$ ), respectively, indicating that $\mathrm{rmGal}-1 \alpha$ behaves as a dimer while rmGal-1 $\beta$ as a monomer. We found that
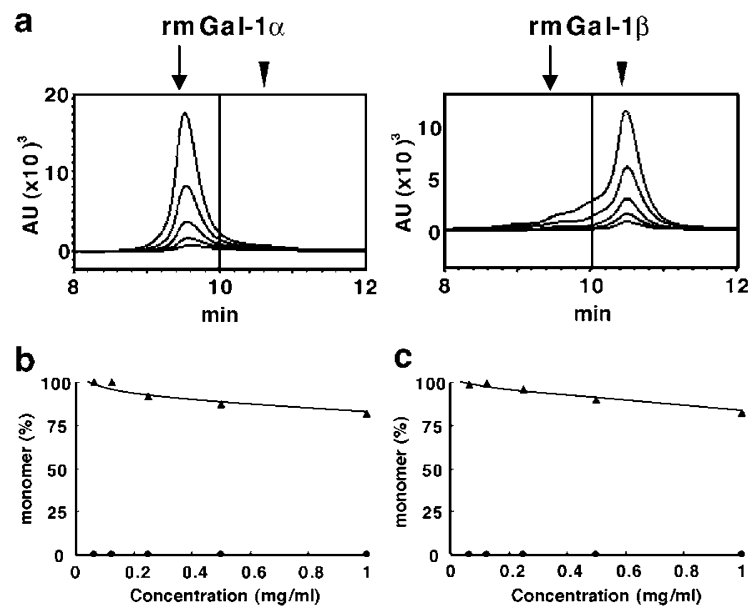

Figure 4 Dimerization of $\mathrm{rmGal}-1 \alpha$ and $\mathrm{rmGal}-1 \beta$ did not depend on its concentration under reduced condition. (a) Monomer-dimer equilibrium of rmGal- $1 \alpha$ and rmGal- $1 \beta$. rmGal- $1 \alpha$ or rmGal- $1 \beta$ was serially diluted from 1 to $0.0625 \mathrm{mg} / \mathrm{ml}$ with PBS containing $4 \mathrm{mM} \beta$-ME, and were incubated at $4^{\circ} \mathrm{C}$ at least for $20 \mathrm{~h}$, and then $10 \mu \mathrm{l}$ of each sample was applied to the size-exclusion HPLC. A chromatogram of each analysis was overlaid. The arrowhead indicates an elution peak of a monomer form and the arrow indicates that of a dimer form. (b) Content of monomer formed at different concentrations of each rmGal-1 $\alpha$ (circles) and rmGal-1 $\beta$ (triangles) was estimated from the peak areas, and plotted against concentration of each protein. (c) The content of the monomer formed at different concentrations of each rmGal- $1 \alpha$ (circles) and rmGal-1 $\beta$ (triangles) in the presence of $10 \mathrm{mM} \beta$-lactose was estimated and plotted
rmGal- $1 \alpha$ behaved exclusively as a dimer at concentrations from $0.0625 \mathrm{mg} / \mathrm{ml}(4.2 \mu \mathrm{M})$ to $1.0 \mathrm{mg} / \mathrm{ml}(67 \mu \mathrm{M})$. In contrast, rmGal-1 $\beta$ behaved mostly as a monomer with a slight trend to form a dimer at higher concentrations (Figure $4 a, b$ ). Essentially, the same results were obtained when experiments were performed with a buffer containing $10 \mathrm{mM}$ $\beta$-lactose (Figure 4c).

\section{Monomerization of $\mathbf{r m G a l}-1 \alpha$ depends on oxidation}

Our results indicate that $\mathrm{rmGal}-1 \alpha$ forms a dimer under reduced conditions. On the other hand, Inagaki et al. ${ }^{29}$ showed that human Gal- $1 \alpha$ oxidized in vitro by air is a monomeric form. Therefore, we examined the possibility that the monomer-dimer equilibrium of $r m G a l-1 \alpha$ may be modulated by redox conditions. Alterations of the monomer-dimer equilibrium of rmGal- $1 \alpha$ during spontaneous oxidation by air at $4^{\circ} \mathrm{C}$ in the presence of various concentrations of $\beta-\mathrm{ME}$, were monitored by size-exclusion HPLC for 50 days (Figure $5 a$ ). The content of the monomer form of $\mathrm{rmGal}-1 \alpha$ increased in a time-dependent manner in the absence or presence of a lower concentration of $\beta$-ME $(0.7 \mathrm{mM})$, and in the former conditions more monomers were formed (Figure $5 \mathrm{a}$ ). In the presence of $14 \mathrm{mM} \beta-\mathrm{ME}, \mathrm{rmGal}-1 \alpha$ remained as a dimer for at least 50 days. Spontaneously oxidized rmGal- $1 \alpha$ by incubation in the absence of $\beta$-ME for 50 days, in which $80 \%$ was a monomer, was completely converted to a dimer $24 \mathrm{~h}$ after incubation in the presence of $14 \mathrm{mM} \beta$-ME (Figure $5 b, d$ ). A monomeric form of rmGal- $1 \alpha$ that oxidized in the presence of $\mathrm{Cu}^{2+}$ was partially converted to a dimeric form $24 \mathrm{~h}$ after incubation in the presence of $4 \mathrm{mM} \beta$-ME (Figure $5 \mathrm{c}, \mathrm{e}$ ). In contrast, rmGal- $1 \beta$ was a monomer form, regardless of incubation for 3 days in the presence of $\beta-\mathrm{ME}$ (Figure 5a).

We thus concluded that the monomer-dimer equilibrium of rmGal- $1 \alpha$ is determined by the redox condition.

\section{Lectin activity of rmGal- $1 \alpha$ and rmGal-1 $\beta$}

The sugar binding activity is another function of galectin-1. To compare their affinity to $\beta$-lactose quantitatively, we used fluorescence spectroscopy to examine the concentrationdependent quenching of the tryptophanyl fluorescence by $\beta$-lactose, since Trp68 residue resides in the lactose binding domain of galectin-1.25 The addition of $\beta$-lactose decreased the fluorescence intensity of both rmGal- $1 \alpha$ and rmGal-1 $\beta$ in a concentration-dependent manner (Figure 6), and the fluorescence peak was shifted to shorter wavelength (data not shown). The binding constant of each protein for $\beta$-lactose was calculated with a simple binding model of one $\beta$-lactose molecule per subunit without any cooperativity $\left(K_{\mathrm{d}}=0.22 \mathrm{mM}\right.$ for rmGal-1 $\alpha$ and $0.50 \mathrm{mM}$ for rmGal-1 $\beta$ ) (Figure 6).

Next, we examined the hemagglutination activity of rmGal$1 \alpha$ and rmGal-1 $\beta$. In the absence of $\beta$-lactose, rmGal- $1 \alpha$ and rmGal-1 $\beta$ induced agglutination at concentrations of $\geqslant 0.98$ and $\geqslant 15.6 \mu \mathrm{g} / \mathrm{ml}$, respectively (Figure $6 \mathrm{~b}$ ). The hemagglutination of each protein was inhibited in the presence of $5 \mathrm{mM} \beta$ lactose, thus confirming that this hemagglutination was a specific activity of each protein (Figure $6 b$ ). 
a

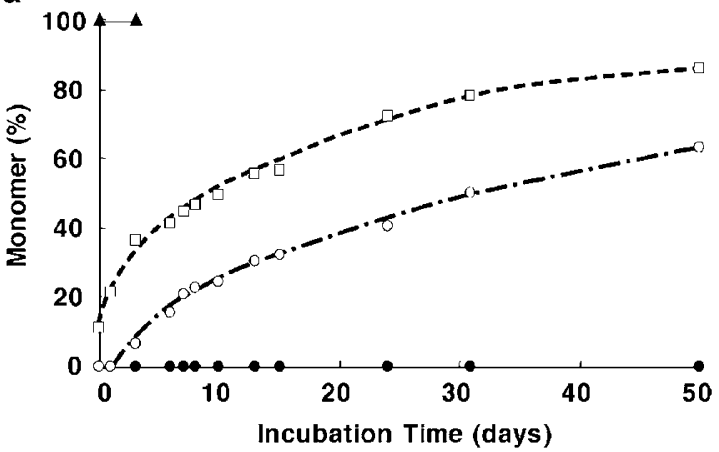

b

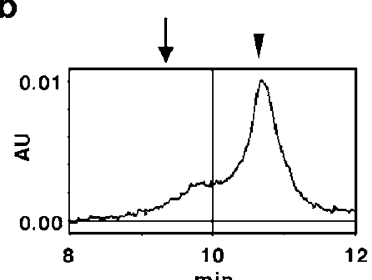

C
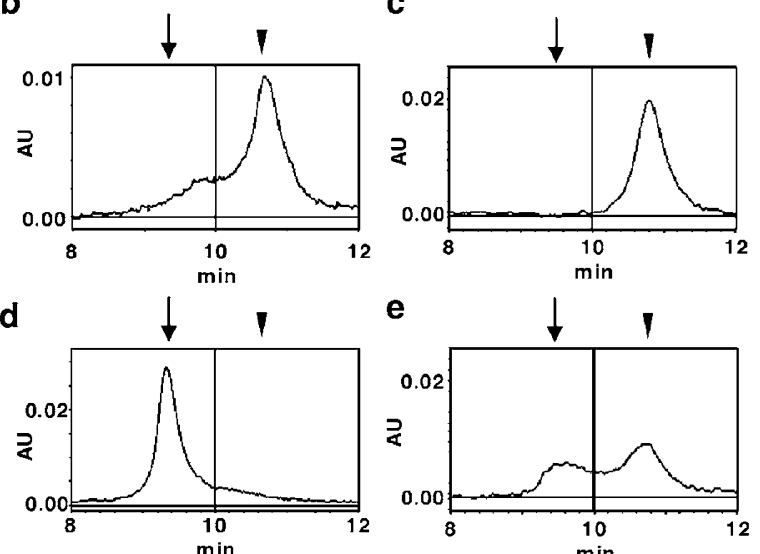

e

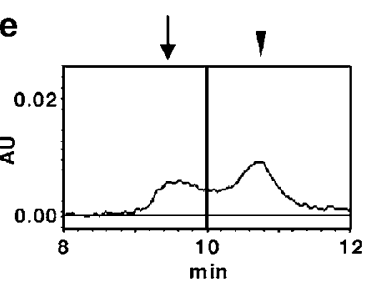

Figure 5 Dimerization of $\mathrm{rmGal}-1 \alpha$ depends on redox conditions. (a) Spontaneous oxidation of rmGal-1 $1 \alpha$. rmGal- $1 \alpha$ were prepared at the concentrations of $0.1 \mathrm{mg} / \mathrm{ml}$ in PBS with $14 \mathrm{mM} \beta$-ME (closed circles) or $0.7 \mathrm{mM} \beta$-ME (open circles) or no $\beta$-ME (open squares). After incubation at $4^{\circ} \mathrm{C}$ for the indicated periods, the content of monomeric rmGal- $1 \alpha$ was determined by the size-exclusion HPLC. The content of monomeric rmGal- $1 \beta$ incubated in the presence of $14 \mathrm{mM} \beta$-ME for 3 days was also determined (closed triangles). (b) Oxidized rmGal- $1 \alpha$ by air exists mostly as a monomer. rmGal- $1 \alpha$, oxidized at $4^{\circ} \mathrm{C}$ for 50 days in the absence of reducing agent was applied to the size-exclusion HPLC. (c) Oxidized rmGal- $1 \alpha$ exists as a monomer. The oxidized rmGal- $1 \alpha$ in the presence of $\mathrm{CuSO}_{4}$ as described in the Materials and Methods, was analyzed by the size-exclusion HPLC. (d) Reversible dimer formation of spontaneously oxidized rmGal- $1 \alpha$. The oxidized rmGal- $1 \alpha$ shown in (b) was incubated in the presence of $14 \mathrm{mM} \beta$-ME for $24 \mathrm{~h}$ at $4{ }^{\circ} \mathrm{C}$, and then was analyzed by sizeexclusion HPLC. (e) Reversible dimer formation of oxidized rmGal-1 $\alpha$. The oxidized rmGal- $1 \alpha$ shown in (d) was incubated in the presence of $4 \mathrm{mM} \beta$-ME at $4^{\circ} \mathrm{C}$ for $24 \mathrm{~h}$, and then it was applied to the size-exclusion HPLC. The arrowhead indicates the elution peak of a monomer form and the arrow indicates that of a dimer form

\section{rmGal-1 $\beta$ lacks an ability to decrease the cell viability}

It has been established that Gal- $1 \alpha$ has an ability to induce apoptosis in activated T cells or some leukemic cell lines such as Jurkat cells. ${ }^{18,36-38}$ We thus examined whether the viability of Jurkat cells decreases with rmGal- $1 \beta$ in comparison to $\mathrm{rmGal}-1 \alpha$. With $0.1 \mathrm{mg} / \mathrm{ml}$ or higher concentrations of rmGal- $1 \alpha$ the viability of Jurkat cells effectively decreased in comparison with PBS control (Figure 7a). In contrast, much higher concentrations of $\mathrm{rmGal}-1 \beta$ slightly decreased the viability of Jurkat cells. After exposure to $0.2 \mathrm{mg} / \mathrm{ml}$ of rmGal- $1 \alpha$, the viability of Jurkat cells decreased to $75 \%$ the

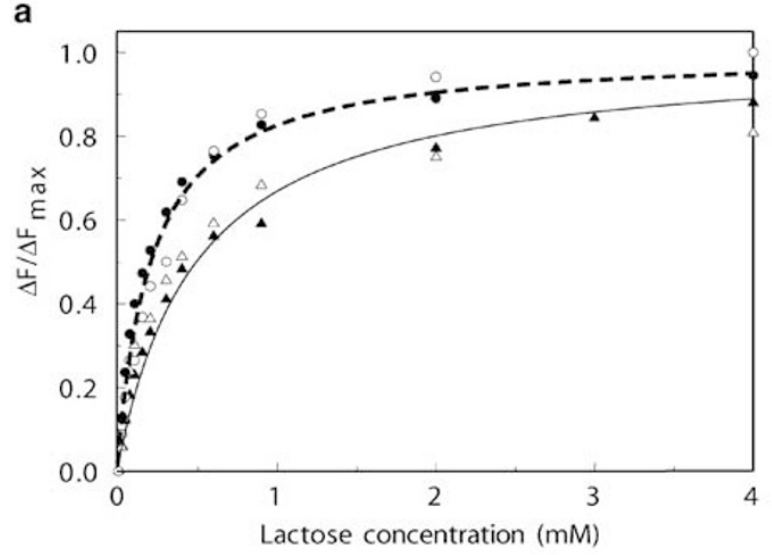

b

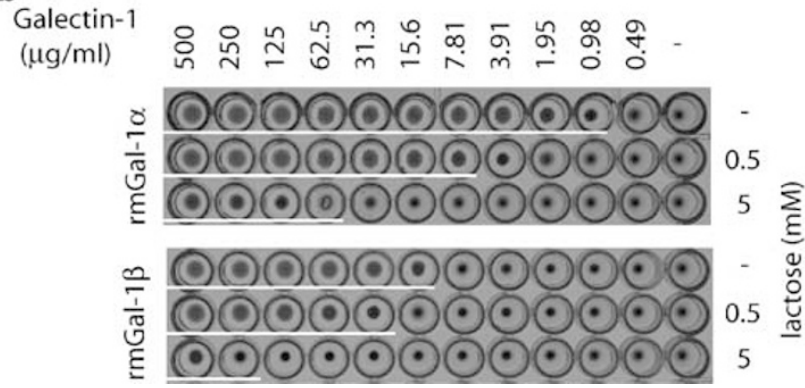

Figure 6 Lectin activity of rmGal- $1 \alpha$ and rmGal-1 $\beta$. (a) Lactose binding activity of rmGal- $1 \alpha$ or rmGal- $1 \beta$. Lactose binding activity of rmGal- $1 \alpha$ (circles) or rmGal$1 \beta$ (triangles) was monitored by their fluorescence change with step-wise addition of $\beta$-lactose. The concentrations of each protein were $50 \mathrm{nM}$ (open symbols) and $500 \mathrm{nM}$ (closed symbols). The best-fit curves for rmGal-1 $\alpha$ $\left(K_{\mathrm{d}}=0.22 \mathrm{mM}\right)$ and $\mathrm{rmGal}-1 \beta\left(K_{\mathrm{d}}=0.50 \mathrm{mM}\right)$ are shown. (b) Hemagglutination activities (HA) of rmGal- $1 \alpha$ and rmGal- $1 \beta$. The hemagglutination activities of rmGal- $1 \alpha$ and rmGal- $1 \beta$ were determined as previously described ${ }^{29}$ In brief, $50 \mu \mathrm{l}$ of $2 \%(\mathrm{v} / \mathrm{v})$ suspension of glutaraldehyde stabilized rabbit red blood cell (INTER-CELL TECHNOLOGIES) was mixed with $50 \mu$ l of various concentrations of $\mathrm{rmGal}-1 \alpha$ or $\mathrm{rmGal}-1 \beta(0.98 \mu \mathrm{g} / \mathrm{ml}$ to $1 \mathrm{mg} / \mathrm{ml})$ prepared in PBS containing $4 \mathrm{mM} \beta$-ME. After incubation at room temperature for $1 \mathrm{~h}$, the hemagglutinating activity was determined based on the sedimentary state of the erythrocytes. The hemagglutinating activity was also determined in the presence of $5 \mathrm{mM}$ or $0.5 \mathrm{mM}$ of $\beta$-lactose. All reactions were performed with U-bottom 96-well microtiter plates (Falcon). The white bars indicate $\mathrm{HA}(+)$ wells a

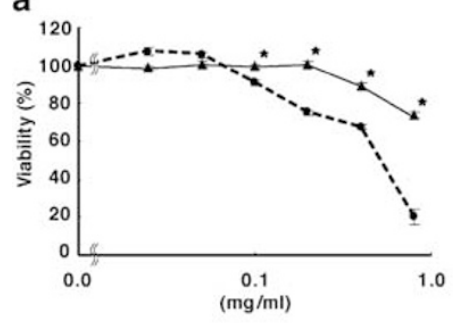

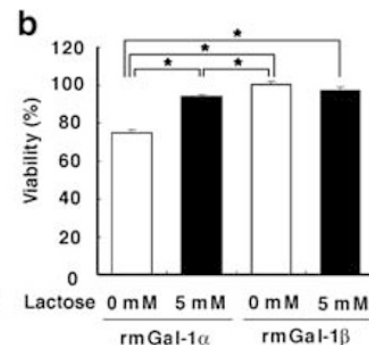

b rmGal-1o rmGal-18
Figure 7 Effects of $r m$ Gal- $1 \alpha$ and rmGal- $1 \beta$ on the viability of Jurkat cells. (a) The viabilities of Jurkat cells after exposure to rmGal- $1 \alpha$ or rmGal- $1 \beta$. Jurkat cells were exposed to indicated concentrations of rmGal- $1 \alpha$ (circles) and rmGal- $1 \beta$ (triangles) for $24 \mathrm{~h}$. The data are expressed as the mean \pm S.E.M. $(n=4-12)$, and then were statistically compared using Mann-Whitney U-tests $\left({ }^{\star} P<0.05\right)$. (b) Effects of $\beta$-lactose on the function of rmGal- $1 \alpha$ or rmGal- $1 \beta$. The viabilities of Jurkat cells after exposure to a concentration of $0.2 \mathrm{mg} / \mathrm{ml}$ of $\mathrm{rmGal}-1 \alpha$ or rmGal$1 \beta$ with (closed bars) or without $\beta$-lactose (open bars). The data are expressed as the mean + S.E.M. $(n=8-12)$, and then are statistically compared by ANOVA (Games-Howell test for multiple comparisons, ${ }^{*} P<0.05$ ) 
level of the control, while in the presence of $5 \mathrm{mM} \beta$-lactose, it was restored to $94 \%$ of the control. On the other hand, rmGal$1 \beta$ did not decrease the viability of Jurkat cells at all with or without $\beta$-lactose (Figure $7 \mathrm{~b}$ ).

\section{rmGal-1 $\beta$ promotes axonal regeneration as efficient as does rmGal- $1 \alpha$}

Horie et al. ${ }^{28,29}$ reported that oxidized human galectin-1 has no lectin activity and behaves as a monomer but it efficiently promotes the regeneration of axons from rat DRG explants. We next examined whether rmGal- $1 \beta$ as well as rmGal- $1 \alpha$ has activity to promote axonal regeneration (Figure 8 ). To eliminate any deleterious effects of $\beta$-ME, we prepared each protein in PBS lacking $\beta$-ME. The number of regenerating axons from the central site of the DRG explants increased significantly with both $\mathrm{rmGal}-1 \alpha$ and $\mathrm{rmGal}-1 \beta$ in a dosedependent manner (Figure $8 \mathrm{c}$ ). With 0.5 or $5 \mathrm{ng} / \mathrm{ml}$ of each protein, about 1.5 times more axons were regenerated from the central site of the DRG explants in comparison to those in the control. In contrast, from the peripheral site of the explants, the maximal number of regenerating axons was observed at a concentration of $0.5 \mathrm{ng} / \mathrm{ml}$ of each protein, and about 1.5 times more axons were regenerated in comparison to those in the control (Figure 8d).

\section{Discussion}

In the present study, we demonstrated that rmGal- $1 \alpha$ forms a homodimer in the presence of reducing agents, within the range of its concentration from 4.2 to $67 \mu \mathrm{M}$ (Figure 4), and that the monomer-dimer equilibrium of rmGal-1 $\alpha$ can be
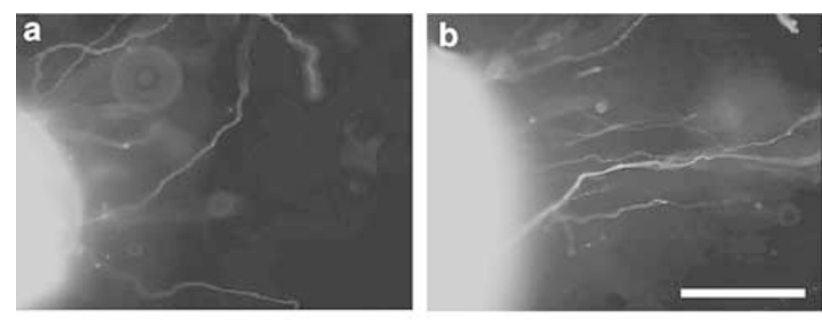

C

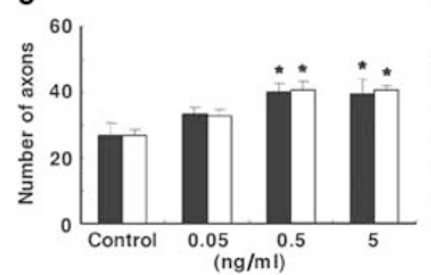

d

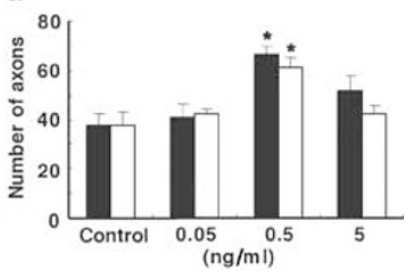

Figure 8 Effects of rmGal- $1 \alpha$ and rmGal- $1 \beta$ on axonal regeneration from the DRG explants. (a, b) Immunofluorescence microscopic identification of regenerating axons from the peripheral site of adult rat DRG explants in the absence (a) or presence of $0.5 \mathrm{ng} / \mathrm{ml}$ of $\mathrm{rmGal}-1 \beta$ (b) $($ scale bar $=200 \mu \mathrm{m})$. (c, d) Promotion of axonal regeneration by $\mathrm{rmGal}-1 \alpha$ and $\mathrm{rmGal}-1 \beta$. The relative number of regenerating axons from central (c) and peripheral (d) sites of the DRG explants in the presence of the indicated concentrations of rmGal-1 $\alpha$ (closed bar) or rmGal-1 $\beta$ (open bar) are shown in comparison with the control. The data are expressed as the mean \pm S.E.M. $(n=8-10)$, and then were statistically compared by ANOVA (Dunnett's test for multiple comparisons, $\left.{ }^{*} P<0.05\right)$ regulated by redox conditions (Figure 5). Cho and Cummings $^{35}$ reported that a mutant form (C2SrGal-1 $\left.\alpha\right)$ of recombinant $\mathrm{Gal}-1 \alpha$ in which the cysteine residue at position 2 (Cys2) was substituted with a serine residue, exists in a reversible monomer-dimer equilibrium with a $K_{\mathrm{d}}=7 \mu \mathrm{M}$. However, Giudicelli et al. ${ }^{39}$ also reported that Gal- $1 \alpha$ exists as a dimeric form even at a low concentration $(2 \mu \mathrm{M})$ in the presence of $1 \mathrm{mM} \beta$-ME using recombinant human galectin-1 (rhGal-1 $\alpha$ ). There are six cysteine residues in a Gal-1 $\alpha$ molecule, and it has been shown that the formation of disulfide bonds abolishes its $\beta$-galactosides-binding activity. In the oxidized Gal-1 $\alpha$, formation of a disulfide bond between residues Cys2 and Cys130 was experimentally demonstrated. $^{29,40}$ It is most likely that a structural alteration of the dimerizing surface consisting of the $\mathrm{N}$ - and $\mathrm{C}$-terminal regions containing Cys2 and Cys130 abolishes the dimer formation. Here, we may suggest that Gal- $1 \alpha$ is one of mediators of the cellular redox status, thus regulating cellular functions to achieve cellular adaptations to the redox status.

We previously reported that $\mathrm{Gal}-1 \beta$, the $\mathrm{N}$-terminally truncated isoform of Gal- $1 \alpha$ was identified as one of molecules whose expression is regulated by $\Delta \mathrm{FosB}$ in cultured rat embryo cell line. ${ }^{6,7}$ Our data obtained by size-exclusion HPLC analyses strongly suggested that rmGla- $1 \beta$ exists mostly as a monomer even in reduced conditions. A protein fluorescence analysis showed that the energy transfer from Tyr119 to Trp69 was smaller in rmGal-1 $\beta$ than in rmGal- $1 \alpha$ which exists as a homodimer, thus indicating that the two residues are apart from each other in the former. Together with these data, we conclude that rmGal-1 $\beta$ exists mostly as a monomer in solution. We showed that affinity of rmGal- $1 \beta$ to $\beta$-lactose was reduced to $44 \%$ levels of that of $\mathrm{rmGal}-1 \alpha$ in reduced conditions, and rmGal-1 $\beta$ retained less than $1 / 16$ levels of hemaggutinating activity observed in rmGal- $1 \alpha$, indicating that $\mathrm{rmGal}-1 \beta$ may not behave as a divalent lectin. We thus conclude that Gal- $1 \beta$ is a natural monomeric form of galectin-1.

Moreover, we showed that $\mathrm{rmGal}-1 \beta$, but not $\mathrm{rmGal}-1 \alpha$ lacks the ability to decrease the viability of Jurkat cells in a lactose-sensitive manner (Figure 7), while rmGal-1 $\beta$ promotes axonal regeneration from the DRG explants as efficient as does rmGal-1 $\alpha$ (Figure 8). These findings are consistent with the monomeric status of rmGal-1 $\beta$. We thus propose that the multifunctional properties of galectin-1 are somehow attributed not only to the redox regulation but also to the presence of two distinctive isoforms, Gal- $1 \alpha$ and Gal-1 $\beta$.

In the DRG, about $20 \%$ of the neurons strongly express galectin-1, and the expression of galectin-1 is considered to likely increase after peripheral nerve injury. ${ }^{41}$ In vitro studies using DRG explants revealed that oxidized Gal- $1 \alpha$ directly stimulates macrophages to secrete a factor that promotes axonal growth; ${ }^{42}$ however, many important questions remain to be answered. Concerning Gal-1 $\beta$, we must clarify whether or not Gal-1 $\beta$ also acts on macrophages, and whether the oxidation of cysteine residues in $\mathrm{Gal}-1 \beta$ is required for such regeneration.

In the central nervous system, galectin-1 in the olfactory system has been shown to be involved in neurite outgrowth and synaptic connectivity during development. In contrast, the expression of $\Delta \mathrm{FosB}$ is highly inducible in the adult brain in 
response to various insults such as ischemic reperfusion injury, ${ }^{43}$ seizure induced by electric stimulation or cocaine administration. ${ }^{44,45}$ We have shown that the expression of $\Delta F o s B$ in cultured cells modulates the cell fate such as cell proliferation, cell differentiation, and cell death accompanied with increased expression of galectin-1. ${ }^{6,7}$ We found that galectin-1 is indeed expressed in the adult mouse hippocampus or cortex ( $T$ Miura and $Y$ Nakabeppu, unpublished data), and that the induction of galectin-1 occurs in the rat hippocampus after ischemic reperfusion injury (H Kurushima and $Y$ Nakabeppu, unpublished data). These observations suggest that the two isoforms of galectin-1, both of which are likely to be induced by $\Delta$ FosB in response to brain damage, either regulate the cell fate or are involved in neurite outgrowth and synaptic connectivity of regenerating neurons. Alterations of the brain function in galectin-1-null and fosB-null mice after such insults are now being examined in our laboratory.

\section{Materials and Methods}

\section{Plasmids}

Mouse Gal- $1 \alpha$ cDNA was amplified by PCR using first-strand CDNA prepared from mouse CCE embryonic stem cell line ${ }^{46}$ as the template with a Gal-1 $\alpha$-specific primer set (GAL1-5-1: GCTGGATCCATGGCCTGTGGTCTG, GAL1-3: GCTGGATCCCTTCACTCAAAGGCCACAC), and was subcloned into pT7Blue T-vector (Novagen), to obtain pT7Blue-mGla- $1 \alpha$. For subcloning, a neutral mutation was introduced at the one of two $\mathrm{Ncol}$ recognition site by recombinant PCR methods using two sets of primers, (M4: GTTTTCCCAGTCACGAC, MuFw: GGCGTCTCCGTGGGCATTGAAGCGAGG) and (MuRv: AATGCCCACGGAGACGCCAACACC, RV: CAGGAAACAGCTATGAC), to obtain pBluescript-rmGal-1 $\alpha$. For the expression of recombinant mouse Gal- $1 \alpha$ (rmGal-1 $\alpha$ ) in $E$. coli, a $\mathrm{Ncol}-\mathrm{BamHI}$ fragment encoding mouse Gal- $1 \alpha$ derived from pBluescriptrmGal- $1 \alpha$ was subcloned into a Ncol-BamHI-digested $\mathrm{pET} 8 \mathrm{c},{ }^{47}$ and pET8c-rmGal- $1 \alpha$ was obtained.

We designed a $5^{\prime}$-primer to place the start codon just in front of the Nterminus of mouse galectin-1 $\beta$, and named GAL1-5-2 (GGTGCTAGCATGAGCAACCTGAATCTCAAACCTGG). Using pT7Blue-mGal-1 $\alpha$ as a template, PCR was performed with a primer set of GAL1-5-2, and GAL1-3, and PCR product was subcloned into PT7Blue T-vector. A Ndel$B a m H I$ fragment encoding mouse Gal- $1 \beta$, in which the Ndel-cleaved end was filled in by Klenow fragment, was subcloned into Nhel/BamHI cleaved $\mathrm{pET3} a,{ }^{47}$ in which the Nhel-cleaved end was filled in by Klenow fragment, to obtain pET3a-mGal-1 $\beta$. All primers used in the present study were obtained from Greiner Japan and the DNA sequences of each plasmid were all confirmed with $\mathrm{ABI}$ Prism Big Dye terminator cycle sequencing kit and ABI PRISM 3100 Genetic Analyzer (PE Applied Biosystems).

\section{Expression and purification of rmGal-1 $\alpha$ and rmGal-1 $\beta$}

E. coli strain of BL21 (CodonPlus RIL) cells (Stratagene) were transformed with $\mathrm{pET} 8 \mathrm{c}-\mathrm{rmGal}-1 \alpha$ or pET3a-mGal- $1 \beta$, and then were grown in an LB medium with $50 \mu \mathrm{g} / \mathrm{ml}$ of ampicillin, at $37^{\circ} \mathrm{C}$ with vigorous shaking. Protein expression was induced by the addition of $1 \mathrm{mM}$ isopropyl $\beta$-Dthiogalactoside to the cultures and cell pellets of approximately $7 \mathrm{~g}$ wet weight were obtained from a $2-1$ culture. The purification of $r m G a l-1 \alpha$ and $\mathrm{rmGal}-1 \beta$ was performed as previously described, ${ }^{48}$ with some modifications. In brief, $E$. coli cell pellets were resuspended with Buffer $T$
(50 mM Tris-HCl (pH 7.6), $100 \mathrm{mM} \mathrm{NaCl}, 14 \mathrm{mM} \beta$-mercaptoethanol ( $\beta$ $\mathrm{ME})$ ) supplemented with protease inhibitor cocktail (Sigma). After being disrupted by sonication, the cell lysate was clarified by centrifugation at $40000 \times g$, for $30 \mathrm{~min}$ at $4^{\circ} \mathrm{C}$. The recovered supernatant was applied to a column packed with lactose-agarose (Seikagaku Corporation) and bound proteins were eluted with Buffer T containing $200 \mathrm{mM} \beta$-lactose (Sigma). Fractions containing the recombinant protein were collected, and then were dialyzed against PBS containing with $4 \mathrm{mM} \beta$-ME. The dialyzed fraction was applied to Detoxi-gel column (Pierce), and the elute was filtered through Millex-GX (Millipore), and was stored at $-80^{\circ} \mathrm{C}$ until use. Column chromatography was performed with the Äkta system (Amersham Bioscience).

\section{Mass spectrometry analysis}

Matrix-assisted laser desorption ionization-time of flight (MALDI-TOF) mass spectra of purified proteins were recorded on an Autoflex mass spectrometer (Bruker Daltonics), in the 6000-22 000 Da mass range, with Protein calibration standard I (Bruker Daltonics). A saturated solution of sinapinic acid in 30\% acetonitrile/0.07\% trifluoroacetic acid (vol/vol) was used as matrix.

\section{Circular dichroism (CD) and fluorescence measurements}

CD spectra were measured using a step mode (bandwidth: $2 \mathrm{~nm}$; interval: $0.1 \mathrm{~nm}$; response time: $0.125 \mathrm{~s}$ ) in a J-810 CD spectrometer (Jasco) equipped with a temperature controller. The spectra were averaged over four scans. Fluorescence was measured in an F-6500 spectrofluorometer (Jasco) equipped with a temperature controller. The emission spectra (bandwidth: $3 \mathrm{~nm}$; response time: $0.5 \mathrm{~s}$; scan rate: $100 \mathrm{~nm} / \mathrm{min}$ ) were measured with excitation at 295 or at $270 \mathrm{~nm}$. The spectra were averaged at least at two scans, and were corrected by subtracting the buffer signal. The experiments were mainly performed in PBS buffer with $1 \mathrm{mM} \beta$-ME. Some $C D$ and fluorescence measurements were performed in $20 \mathrm{mM}$ sodium phosphate with $1 \mathrm{mM} \beta$-ME. The buffers were degassed just before use.

\section{Size-exclusion HPLC}

To separate the monomeric and dimeric forms of rmGal- $1 \alpha$ or $\mathrm{rmGal}-1 \beta$, size-exclusion HPLC was performed as described previously, ${ }^{35}$ except for using Class-VP HPLC System (Shimazu) equipped with TSK-GEL superSW2000 column (Tosoh). The column was equilibrated with PBS containing $4 \mathrm{mM}$ or $14 \mathrm{mM}$ of $\beta$-ME and $10 \mu \mathrm{l}$ of the sample was injected into the column. Separation was carried out isocratically at $0.35 \mathrm{ml} / \mathrm{min}$ for $25 \mathrm{~min}$. The elution of protein was monitored by absorbance at $214 \mathrm{~nm}$.

\section{Preparation of oxidized $\mathrm{rmGal}-1 \alpha$}

rmGal- $1 \alpha$ was oxidized in the presence of $\mathrm{CuSO}_{4}$ as described previously. ${ }^{29}$ The solution of rmGal- $1 \alpha(45.5 \mu \mathrm{g} / \mathrm{ml}$ in $20 \mathrm{mM}$ Tris- $\mathrm{HCl}$ (pH 8.0)) was prepared in a Slide-A-Lyzer (MWCO: 3500, Pierce), and oxidation was performed by dialysis of the solution in the Slide-A-Lyzer against the buffer containing $0.0001 \%(\mathrm{w} / \mathrm{v}) \mathrm{CuSO}_{4}$ at $4{ }^{\circ} \mathrm{C}$ for 2 days. The solution was further dialyzed against $10 \mathrm{mM}$ Tris- $\mathrm{HCl}(\mathrm{pH} 7.5) / 10 \mathrm{mM} \mathrm{NaCl}$ for two days, and was applied to a HitrapQ column (Amersham Biosciences). Bound Gal- $1 \alpha$ was eluted with a linear gradient of $10 \mathrm{mM}$ to 
$1 \mathrm{M} \mathrm{NaCl}$ in $10 \mathrm{mM}$ Tris- $\mathrm{HCl}(\mathrm{pH} \mathrm{7.5)}$, and fractions containing the monomeric Gal- $1 \alpha$ were pooled and used as oxidized Gal- $1 \alpha$.

\section{Jurkat cell culture and viability assay}

The Jurkat E6.1. cell line was obtained from ATCC and cultured in RPMl1640 medium (Gibco) supplemented with $4.5 \mathrm{~g} / \mathrm{l}$ glucose, $10 \mathrm{mM}$ HEPES, $1 \mathrm{mM}$ sodium pyruvate and $10 \%$ heat-inactivated FBS. Exponentially growing Jurkat cells were prepared at $4 \times 10^{5} \mathrm{cells} / \mathrm{ml}$ in RPMI 1640 medium supplemented with $1 \%$ heat-inactivated FBS. Various concentrations of $r \mathrm{Gal}-1 \alpha$ or rmGal- $1 \beta$ were prepared in PBS containing $4 \mathrm{mM} \beta$-ME. A volume of $75 \mu \mathrm{l}$ of the cell suspension was mixed with $25 \mu \mathrm{l}$ of $\mathrm{rmGal}-1 \alpha$ or rmGal- $1 \beta$ solution in flat-bottom 96 -well microtiter plates (Sumilon), and the mixture was incubated at $37^{\circ} \mathrm{C}$ in a $\mathrm{CO}_{2}$ incubator for $24 \mathrm{~h}$. The number of viable cells was estimated by CellTiter-Glo ${ }^{\mathrm{TM}}$ Luminescent Cell Viability Assay (Promega) and Walloc 1420 ARVO multilabel counter (Perkin-Elmer).

\section{Assay for axonal regeneration in vitro and immunohistochemical identification of regenerated axons}

Axonal regeneration was detected with a three-dimensional culture of adult rat DRG explants embedded in collagen gel as described previously. ${ }^{27,49}$ During the experiment (for 7 days), either rmGal- $1 \alpha$ or rmGal- $1 \beta$ was added to the culture system at a final concentration of 0.05 , 0.5 and $5 \mathrm{ng} / \mathrm{ml}$. For immunofluorescence microscopy, the tissues were fixed with 4\% paraformaldehyde. An anti- $\beta$ III tubulin monoclonal antibody (Promega) was applied to the fixed tissues in $0.3 \%$ Triton X-100 in PBS for 2 days. A FITC-labeled goat anti-mouse IgG antibody (Chemicon) was applied for 2 days. The tissue was observed with a fluorescence microscope (Nikon TE 300) equipped with a color chilled 3CCD camera (Hamamatsu, C5810).

\section{Acknowledgements}

We extend our special thanks to Drs. S Hirano, M Furuichi, $Y$ Tominaga, T Kadoya, S Kanba and Y Ohnishi for helpful discussions, and to Dr. B Quinn for useful comments on this manuscript.

\section{References}

1. Nakabeppu Y, Ryder $\mathrm{K}$ and Nathans D (1988) DNA binding activities of three murine Jun proteins: stimulation by Fos. Cell 55: 907-915

2. Chinenov $Y$ and Kerppola TK (2001) Close encounters of many kinds: Fos-Jun interactions that mediate transcription regulatory specificity. Oncogene 20: 2438-2452

3. Jochum W, Passegué E and Wagner EF (2001) AP-1 in mouse development and tumorigenesis. Oncogene 20: 2401-2412

4. Shaulian E and Karin M (2001) AP-1 in cell proliferation and survival. Oncogene 20: $2390-2400$

5. Nakabeppu $Y$ and Nathans D (1991) A naturally occurring truncated form of FosB that inhibits Fos/Jun transcriptional activity. Cell 64: 751-759

6. Nishioka T, Sakumi K, Miura T, Tahara K, Horie H, Kadoya T and Nakabeppu Y (2002) FosB gene products trigger cell proliferation and morphological alteration with an increased expression of a novel processed form of galectin-1 in the rat 3Y1 embryo cell line. J. Biochem. (Tokyo) 131: 653-661

7. Tahara K, Tsuchimoto D, Tominaga Y, Asoh S, Ohta S, Kitagawa M, Horie H, Kadoya T and Nakabeppu Y (2003) DeltaFosB, but not FosB, induces delayed apoptosis independent of cell proliferation in the Rat1a embryo cell line. Cell Death Differ. 10: 496-507
8. Barondes SH, Castronovo V, Cooper DN, Cummings RD, Drickamer K, Feizi T, Gitt MA, Hirabayashi J, Hughes C, Kasai K, Leffler H, Liu F-T, Lotan R, Mercurio AM, Monsigny M, Pillai S, Poirier F, Raz A, Rigby PW, Rini JM and Wang JL (1994) Galectins: a family of animal beta-galactoside-binding lectins. Cell 76: 597-598

9. de Waard A, Hickman S and Kornfeld S (1976) Isolation and properties of beta-galactoside binding lectins of calf heart and lung. J. Biol. Chem. 251: $7581-7587$

10. Poirier F, Timmons PM, Chan CT, Guénet JL and Rigby PW (1992) Expression of the L14 lectin during mouse embryogenesis suggests multiple roles during pre- and post-implantation development. Development 115: 143-155

11. Allen HJ, Gottstine S, Sharma A, DiCioccio RA, Swank RT and Li H (1991) Synthesis, isolation, and characterization of endogenous beta-galactosidebinding lectins in human leukocytes. Biochemistry 30: 8904-8910

12. Levi $G$ and Teichberg VI (1984) The distribution of electrolectin in mouse: genetic and ontogenic variations. Biochem. Biophys. Res. Commun. 119: 801-806

13. Catt JW, Harrison FL and Carleton JS (1987) Distribution of an endogenous beta-galactoside-specific lectin during foetal and neonatal rabbit development. J. Cell. Sci. 87 (Part 5): 623-633

14. Powell JT (1980) Purification and properties of lung lectin. Rat lung and human lung beta-galactoside-binding proteins. Biochem. J. 187: 123-129

15. Hirabayashi J and Kasai K (1984) Human placenta beta-galactoside-binding lectin. Purification and some properties. Biochem. Biophys. Res. Commun. 122: $938-944$

16. Allen HJ, Sucato D, Woynarowska B, Gottstine S, Sharma A and Bernacki RJ (1990) Role of galaptin in ovarian carcinoma adhesion to extracellular matrix in vitro. J. Cell. Biochem. 43: 43-57

17. Wells $V$ and Mallucci $L$ (1991) Identification of an autocrine negative growth factor: mouse beta-galactoside-binding protein is a cytostatic factor and cell growth regulator. Cell 64: 91-97

18. Perillo NL, Pace KE, Seilhamer JJ and Baum LG (1995) Apoptosis of T cells mediated by galectin-1. Nature 378: 736-739

19. Perillo NL, Uittenbogaart CH, Nguyen JT and Baum LG (1997) Galectin-1, an endogenous lectin produced by thymic epithelial cells, induces apoptosis of human thymocytes. J. Exp. Med. 185: 1851-1858

20. Paz A, Haklai R, Elad-Sfadia G, Ballan E and Kloog Y (2001) Galectin-1 binds oncogenic $\mathrm{H}$-Ras to mediate Ras membrane anchorage and cell transformation. Oncogene 20: 7486-7493

21. Elad-Sfadia G, Haklai R, Ballan E, Gabius HJ and Kloog Y (2002) Galectin-1 augments Ras activation and diverts Ras signals to Raf-1 at the expense of phosphoinositide 3-kinase. J. Biol. Chem. 277: 37169-37175

22. Vyakarnam A, Lenneman AJ, Lakkides KM, Patterson RJ and Wang JL (1998) A comparative nuclear localization study of galectin-1 with other splicing components. Exp. Cell. Res. 242: 419-428

23. Park JW, Voss PG, Grabski S, Wang JL and Patterson RJ (2001) Association of galectin-1 and galectin-3 with Gemin 4 in complexes containing the SMN protein. Nucleic Acids Res. 29: 3595-3602

24. Clerch LB, Whitney P, Hass M, Brew K, Miller T, Werner R and Massaro D (1988) Sequence of a full-length CDNA for rat lung beta-galactoside-binding protein: primary and secondary structure of the lectin. Biochemistry 27: 692699

25. Liao DI, Kapadia G, Ahmed H, Vasta GR and Herzberg O (1994) Structure of Slectin, a developmentally regulated vertebrate beta-galactoside-binding protein. Proc. Natl. Acad. Sci. USA 91: 1428-1432

26. Bourne $Y$, Bolgiano B, Nésa MP, Penfold $P$, Johnson D, Feizi T and Cambillau C (1994) Crystallization and preliminary X-ray diffraction studies of the soluble $14 \mathrm{kDa}$ beta-galactoside-binding lectin from bovine heart. J. Mol. Biol. 235: 787-789

27. Horie H, Inagaki Y, Sohma Y, Nozawa R, Okawa K, Hasegawa M, Muramatsu N, Kawano H, Horie M, Koyama H, Sakai I, Takeshita K, Kowada Y, Takano M and Kadoya T (1999) Galectin-1 regulates initial axonal growth in peripheral nerves after axotomy. J. Neurosci. 19: 9964-9974

28. Horie $\mathrm{H}$ and Kadoya $\mathrm{T}$ (2000) Identification of oxidized galectin-1 as an initial repair regulatory factor after axotomy in peripheral nerves. Neurosci. Res. 38: 131-137

29. Inagaki $Y$, Sohma $Y$, Horie H, Nozawa R and Kadoya $T$ (2000) Oxidized galectin-1 promotes axonal regeneration in peripheral nerves but does not possess lectin properties. Eur. J. Biochem. 267: 2955-2964 
30. Cho M and Cummings RD (1996) Characterization of monomeric forms of galectin-1 generated by site-directed mutagenesis. Biochemistry 35 : $13081-13088$

31. Yang JT, Wu CS and Martinez HM (1986) Calculation of protein conformation from circular dichroism. Methods Enzymol. 130: 208-269

32. Johnson Jr WC (1990) Protein secondary structure and circular dichroism: a practical guide. Proteins 7: 205-214

33. Barondes SH, Cooper DN, Gitt MA and Leffler H (1994) Galectins. Structure and function of a large family of animal lectins. J. Biol. Chem. 269: 20807-20810

34. Lakowics JR (1999) Principles of Fluorescence Spectroscopy, 2nd ed. New York: Plenum publishers pp 456-458

35. Cho M and Cummings RD (1995) Galectin-1, a beta-galactoside-binding lectin in Chinese hamster ovary cells.I. Physical and chemical characterization. J. Biol. Chem. 270: 5198-5206

36. Fouillit M, Lévi-Strauss M, Giudicelli V, Lutomski D, Bladier D, Caron M and Joubert-Caron R (1998) Affinity purification and characterization of recombinant human galectin-1. J. Chromatogr. B Biomed. Sci. Appl. 706: 167-171

37. Walzel H, Schulz U, Neels P and Brock J (1999) Galectin-1, a natural ligand for the receptor-type protein tyrosine phosphatase CD45. Immunol. Lett. 67: 193-202

38. Fajka-Boja R, Szemes M, Ion G, Légrádi A, Caron M and Monostori E (2002) Receptor tyrosine phosphatase, CD45 binds galectin- 1 but does not mediate its apoptotic signal in T cell lines. Immunol. Lett. 82: 149-154

39. Giudicelli V, Lutomski D, Lévi-Strauss M, Bladier D, Joubert-Caron R and Caron M (1997) Is human galectin-1 activity modulated by monomer/dimer equilibrium? Glycobiology 7 viii-x

40. Tracey BM, Feizi T, Abbott WM, Carruthers RA, Green BN and Lawson AM (1992) Subunit molecular mass assignment of $14,654 \mathrm{Da}$ to the soluble betagalactoside-binding lectin from bovine heart muscle and demonstration of intramolecular disulfide bonding associated with oxidative inactivation. J. Biol. Chem. 267: 10342-10347
41. Imbe H, Okamoto K, Kadoya T, Horie H and Senba E (2003) Galectin-1 is involved in the potentiation of neuropathic pain in the dorsal horn. Brain Res. 993: 72-83

42. Horie H, Kadoya T, Hikawa N, Sango K, Inoue H, Takeshita K, Asawa R, Hiroi T, Sato M, Yoshioka T and Ishikawa Y (2004) Oxidized galectin-1 stimulates macrophages to promote axonal regeneration in peripheral nerves after axotomy. J. Neurosci. 24: 1873-1880

43. McGahan L, Hakim AM, Nakabeppu $Y$ and Robertson GS (1998) Ischemia-induced CA1 neuronal death is preceded by elevated FosB and Jun expression and reduced NGFI-A and JunB levels. Brain Res. Mol. Brain Res. 56: 146-161

44. Hope BT, Nye HE, Kelz MB, Self DW, ladarola MJ, Nakabeppu Y, Duman RS and Nestler EJ (1994) Induction of a long-lasting AP-1 complex composed of altered Fos-like proteins in brain by chronic cocaine and other chronic treatments. Neuron 13: 1235-1244

45. Chen J, Nye HE, Kelz MB, Hiroi N, Nakabeppu Y, Hope BT and Nestler EJ (1995) Regulation of delta FosB and FosB-like proteins by electroconvulsive seizure and cocaine treatments. Mol. Pharmacol. 48: 880-889

46. Hirano S, Tominaga Y, Ichinoe A, Ushijima Y, Tsuchimoto D, Honda-Ohnishi Y, Ohtsubo T, Sakumi K and Nakabeppu Y (2003) Mutator phenotype of MUTYH-null mouse embryonic stem cells. J. Biol. Chem. 278: 38121-38124

47. Studier FW, Rosenberg AH, Dunn JJ and Dubendorff JW (1990) Use of T7 RNA polymerase to direct expression of cloned genes. Methods Enzymol. 185: 60-89

48. Bladier D, Joubert R, Avellana-Adalid V, Kemeny JL, Doinel C, Amouroux J and Caron M (1989) Purification and characterization of a galactoside-binding lectin from human brain. Arch. Biochem. Biophys. 269: 433-439

49. Horie H, Sakai I, Akahori Y and Kadoya T (1997) IL-1 beta enhances neurite regeneration from transected-nerve terminals of adult rat DRG. NeuroReport 8 : 1955-1959

50. Martz E (2002) Protein explorer: easy yet powerful macromolecular visualization. Trends Biochem. Sci. 27: 107-109 